\title{
8-10-2017
}

\section{Influence of Differential Calcification in the Descending Thoracic Aorta on Aortic Pulse Pressure}

\author{
Mirza Mujadil Ahmad \\ Syed Haris Ahmed Pir \\ Mustafa Noor Muhammad \\ Sharmeen Hussaini \\ Immad Arif Kiani \\ Mirza Nubair Ahmad \\ Imaad Razzaque \\ Muhammad Nabeel Syed \\ Rafath Ullah \\ Suhail Allaqaband \\ See next page for additional authors \\ Follow this and additional works at: https://aah.org/jpcrr \\ Part of the Cardiology Commons, Cardiovascular Diseases Commons, Cardiovascular System \\ Commons, and the Other Analytical, Diagnostic and Therapeutic Techniques and Equipment Commons
}

\section{Recommended Citation}

Ahmad MM, Pir SHA, Muhammad MN, Hussaini S, Kiani IA, Ahmad MN, Razzaque I, Syed MN, Ullah R, Allaqaband S, Gupta A, Port SC, Ammar KA. Influence of differential calcification in the descending thoracic aorta on aortic pulse pressure. J Patient Cent Res Rev. 2017;4:104-13. doi: 10.17294/ 2330-0698.1448

Published quarterly by Midwest-based health system Advocate Aurora Health and indexed in PubMed Central, the Journal of Patient-Centered Research and Reviews (JPCRR) is an open access, peer-reviewed medical journal focused on disseminating scholarly works devoted to improving patient-centered care practices, health outcomes, and the patient experience. 


\section{Influence of Differential Calcification in the Descending Thoracic Aorta on Aortic Pulse Pressure}

\section{Authors}

Mirza Mujadil Ahmad, Syed Haris Ahmed Pir, Mustafa Noor Muhammad, Sharmeen Hussaini, Immad Arif Kiani, Mirza Nubair Ahmad, Imaad Razzaque, Muhammad Nabeel Syed, Rafath Ullah, Suhail Allaqaband, Anjan Gupta, Steven C. Port, and Khawaja Afzal Ammar 


\title{
Influence of Differential Calcification in the Descending Thoracic Aorta on Aortic Pulse Pressure
}

\author{
*Mirza Mujadil Ahmad, MD, *Syed Haris Ahmed Pir, MD, Mustafa Noor Muhammad, MD, Sharmeen \\ Hussaini, MD, Immad Arif Kiani, MD, Mirza Nubair Ahmad, MD, Imaad Razzaque, MD, Muhammad \\ Nabeel Syed, MD, Rafath Ullah, MD, Suhail Allaqaband, MD, Anjan Gupta, MD, Steven C. Port, MD, \\ Khawaja Afzal Ammar, MD
}

Aurora Cardiovascular Services, Aurora Sinai/Aurora St. Luke’s Medical Centers, Milwaukee, WI

\begin{abstract}
Purpose Multiple studies have shown pulse pressure (PP) to be a strong predictor of aortic calcification. However, no studies are available that correlate PP with aortic calcification at the segmental level.

Methods We identified 37 patients with aortic PP measured during cardiac catheterization. Their noncontrast chest computed tomography scans were evaluated for the presence of calcium in different segments (ascending aorta, arch of aorta [arch], descending aorta) and quantified. Patients with calcification (Calcified Group A) were compared against patients without calcification (Noncalcified Group B) in terms of PP, calcification and compliance.
\end{abstract}

Results The mean of the total calcium score was higher in the descending aorta than the arch or ascending aorta (691 vs 571 vs 131, respectively, $\mathrm{P}<0.0001$ ). PP had the strongest correlation with calcification in the descending aorta ( $r=0.47, P=0.004)$. Calcified Group A had a much higher PP than Noncalcified Group B, with the greatest difference in the descending aorta $(20 \mathrm{mmHg}, \mathrm{P}<0.0001)$, lesser in the ascending aorta $(10 \mathrm{mmHg}, \mathrm{P}=0.12)$ and the least in the arch $(5 \mathrm{mmHg}, \mathrm{P}=0.38)$. Calcified Group A patients also had much lower compliance than Noncalcified Group B patients, with the greatest difference among groups seen in the descending aorta $(0.7 \mathrm{~mL} / \mathrm{mmHg}, \mathrm{P}=0.002)$, followed by the ascending aorta, then arch.

Conclusions These are the first data to evaluate the relative impact of aortic segments in PP. Finding the greatest amount of calcification along with greatest change in PP and compliance in the descending aorta makes a case that the descending aorta plays a major role in PP as compared to other segments of the thoracic aorta. (J Patient Cent Res Rev. 2017;4:104-113.)

Keywords thoracic aortic, calcification, pulse pressure, compliance, computed tomography

$\mathrm{P}$ ulse pressure (PP) is defined as the difference between systolic blood pressure and diastolic blood pressure. PP progressively increases with age due to decreasing arterial compliance attributed to calcification in the arterial walls. ${ }^{1}$ Multiple prior epidemiological studies have shown that increasing PP is correlated with cardiovascular morbidity and mortality. ${ }^{2,3}$

*These authors contributed equally to this work.

Correspondence: Khawaja Afzal Ammar, MD

Aurora St. Luke's Medical Center, 2801 W. Kinnickinnic

River Parkway, \#840, Milwaukee, WI, 53215,

T: +1-414-649-3909, Email: publishing28@aurora.org
Prior studies, using different imaging modalities, have independently measured the amount of calcification in the abdominal aorta, carotid, ${ }^{4}$ femoral and iliofemoral arteries. ${ }^{5}$ These studies have correlated the calcification with hemodynamic indices and have established the link between calcification and PP $(\beta=0.4, \mathrm{P}<0.01){ }^{6}$

One study reported a greater number of calcified lesions in the descending thoracic aorta than its other segments, especially the ascending thoracic aorta. ${ }^{7}$ Histopathological studies have demonstrated, albeit in a relatively young and healthy selected cohort, that elastic fiber concentration progressively decreases 
from the ascending aorta to the descending thoracic aorta. ${ }^{8}$ These two observations suggest that the descending thoracic aorta may be stiffer and therefore could have a greater impact on PP. However, no studies have evaluated the association between differing levels of calcification in the various segments of the thoracic aorta and the relative impact on PP.

Since elastic fibers would increase compliance and calcification would decrease compliance, we hypothesized that aortic PP would be associated in a differential fashion in different segments of the aorta. To test this hypothesis, we measured calcification levels in aortic segments by computed tomography (CT), PP via noninvasive and invasive measurements, and compliance by the Windkessel model. ${ }^{9}$

\section{METHODS}

\section{Study Population}

This study was reviewed and approved by the local institutional review board. We identified 405 patients who had undergone a cardiac catheterization in which direct aortic pressure was measured by end-hole catheter in the ascending aorta near the ostium of the left main coronary artery at our tertiary care center from January 1, 2011, to November 30, 2014. Electronic medical records of these patients were then searched for availability of noncontrast CT scans. Only those patients who had a noncontrast CT scan 12 months prior to or after their cardiac catheterization were included. Patients who had coarctation of the aorta, moderate or worse aortic stenosis, or regurgitation were not included. This yielded a study cohort of 37 patients.

\section{Demographics}

Through chart review, we obtained the risk factors for arterial calcification. These included hypertension, dyslipidemia, diabetes mellitus, chronic kidney disease and smoking. Values from the notes made prior to the cardiac catheterization procedure were used. Age, diabetes mellitus, hypertension, dyslipidemia, smoking and chronic kidney disease were compared between male and female patients to discern differences in distribution.

\section{Pulse Pressure}

PP was calculated from noninvasive cuff blood pressure measurements during echocardiography. In addition, PP was measured invasively during cardiac catheterization, with the guide catheter in the ascending aorta near the ostium of the coronary arteries. The patients selected were undergoing fractional flow reserve measurement in which the guide catheter measured PP in the ascending aorta. This method has the superiority provided by invasive measurement but also inferiority due to nonsimultaneous taking of measurements.

\section{Measurement of Calcification}

A CT scan provides different indices for the measurement of calcification. Total calcium score $(\mathrm{CaSc})$ quantifies the amount of calcium in the segment, whereas calcium volume is the total number of voxels (volumetric unit of a CT scan) that have calcification. Mean CaSc indicates the density of calcification per voxel.

Calcification indices of the thoracic aorta and its segments (ascending aorta, arch of the aorta, descending aorta) were manually measured from noncontrast and nongated CT scans the patients had undergone for clinical reasons. Although most calcium scoring studies have preferred using gated CT scans, recent data suggest that nongated CT scans can be used for calcium scoring with reasonable accuracy. ${ }^{10}$ Further allaying concerns regarding precision, electrocardiogram gating is a technique primarily used to adequately image highly mobile coronary arteries, whereas the focus of our study was the aorta, which is relatively fixed to the thoracic wall.

\section{Compliance}

Echocardiographic reports done within a year of catheterization were used to obtain blood pressure and stroke volume (SV) for measuring compliance of the aorta. SV was measured from Doppler echocardiography based on the continuity equation (in which LVOT indicates left ventricular outflow tract):

$$
\begin{gathered}
\text { Flow }=\text { Area } \times \text { Velocity } \\
S V=\left(\frac{\text { LVOT Diameter }}{2}\right)^{2} \pi \times \text { Time Velocity Integral }
\end{gathered}
$$

Compliance was measured as a function of change in volume (V) and pressure (P). It was calculated using both invasively and noninvasively obtained PP.

$$
\begin{gathered}
\text { Compliance }=\frac{\Delta V}{\Delta P} \\
\text { Aortic Compliance }=\frac{S V}{P P}
\end{gathered}
$$




\section{Statistical Analysis}

In order to evaluate the associations of the presence of calcium with compliance and PP independently in each segment of the aorta, patients were stratified into two groups for each segment: Calcified Group A had calcification, and Noncalcified Group B did not. A simple t-test was used to compare PP and compliance, separately, between groups. We applied linear regression and Spearman's rank correlation to compare aortic PP with calcifications. Standardized beta $(\operatorname{Std} \beta)$ was used due to the markedly different ranges of our parameters, ie, PP ranges from 40 to $60 \mathrm{mmHg}$ compared with $\mathrm{CaSc}$ ranges from 0 to 14,000 .

\section{RESULTS \\ Demographics}

Our sample population was $60 \%$ men $(n=22)$ and $40 \%$ women $(\mathrm{n}=15)$. Mean age at the time of cardiac catheterization procedure was $64.3 \pm 9.7$ years. The mean age for men ( $65.6 \pm 11$ years) was higher than for women (62.2 \pm 6.2 years) but did not reach statistical significance $(\mathrm{P}=0.29)($ Table 1$)$.

Most patients had hypertension (95\%) or diabetes mellitus $(86.5 \%)$, and a minority had dyslipidemia $(27 \%)$ or chronic kidney disease $(5 \%)$ with a glomerular filtration rate $<30 \mathrm{~mL} / \mathrm{min}$ (stages 4 and 5). The difference in the distribution of these risk factors between the sexes was not statistically significant.

Table 1. Baseline Characteristics of Study Population

\begin{tabular}{|c|c|c|c|c|}
\hline Characteristic & $\begin{array}{c}\text { All } \\
(n=37)\end{array}$ & $\begin{array}{c}\text { Men } \\
(n=22)\end{array}$ & $\begin{array}{c}\text { Women } \\
(n=15)\end{array}$ & $P$ \\
\hline \multicolumn{5}{|l|}{ Demographics } \\
\hline Age, years \pm SD & $64.3 \pm 9.7$ & $65.6 \pm 11.5$ & $62.2 \pm 6.2$ & 0.29 \\
\hline Diabetes mellitus, $\mathrm{n}(\%)$ & $10(27 \%)$ & $6(27 \%)$ & $4(11 \%)$ & 0.97 \\
\hline Hypertension, n (\%) & $35(95 \%)$ & $21(95 \%)$ & $14(93 \%)$ & 0.78 \\
\hline Dyslipidemia, n (\%) & $32(86.5 \%)$ & $20(91 \%)$ & $12(80 \%)$ & 0.34 \\
\hline Smoking, $\mathrm{n}(\%)$ & $30(81 \%)$ & $22(100 \%)$ & $8(53 \%)$ & $<0.0001$ \\
\hline Chronic kidney disease, n (\%) & $2(5.4 \%)$ & $2(9.1 \%)$ & $0(0.0 \%)$ & 0.15 \\
\hline \multicolumn{5}{|l|}{ Hemodynamic indices, $\mathrm{mmHg} \pm \mathrm{SD}$} \\
\hline Systolic blood pressure & $122.6 \pm 20.9$ & $122.5 \pm 24.5$ & $122.7 \pm 15.2$ & 0.99 \\
\hline Diastolic blood pressure & $67.1 \pm 11.6$ & $69.5 \pm 12.9$ & $63.6 \pm 8.6$ & 0.13 \\
\hline Invasive pulse pressure & $55.5 \pm 17.8$ & $53 \pm 17.7$ & $59 \pm 17.9$ & 0.32 \\
\hline Noninvasive pulse pressure & $52.3 \pm 16$ & $54.6 \pm 17$ & $49.2 \pm 15$ & 0.36 \\
\hline \multicolumn{5}{|l|}{ Total calcification, $\mathrm{CaSc} \pm \mathrm{SD}$} \\
\hline Arch of aorta & $571.1 \pm 1127.8$ & $777.8 \pm 1406$ & $267.9 \pm 373.6$ & 0.18 \\
\hline Ascending aorta & $131.3 \pm 395.7$ & $190.7 \pm 492.5$ & $43.9 \pm 158.2$ & 0.27 \\
\hline Descending thoracic aorta & $697.2 \pm 1521.7$ & $970.8 \pm 1914.8$ & $295.9 \pm 405.1$ & 0.19 \\
\hline \multicolumn{5}{|l|}{ Mean calcification, $\mathrm{CaSc} \pm \mathrm{SD}$} \\
\hline Arch of aorta & $183.7 \pm 149$ & $210 \pm 134$ & $145 \pm 166.7$ & 0.2 \\
\hline Ascending aorta & $77.8 \pm 130$ & $82.7 \pm 130$ & $70.5 \pm 134.5$ & 0.8 \\
\hline Descending thoracic aorta & $190 \pm 189$ & $188.6 \pm 177.9$ & $192.3 \pm 200.9$ & 0.95 \\
\hline \multicolumn{5}{|l|}{ Compliance, $\mathrm{mL} / \mathrm{mmHg} \pm \mathrm{SD}$} \\
\hline Invasive & $1.48 \pm 0.65$ & $1.55 \pm 0.74$ & $1.38 \pm 0.53$ & 0.52 \\
\hline Noninvasive & $1.49 \pm 0.55$ & $1.43 \pm 0.59$ & $1.59 \pm 0.51$ & 0.45 \\
\hline
\end{tabular}

CaSc, calcium score; SD, standard deviation. 
Smoking was two times more prevalent in men than women $(100 \%$ vs $53 \%, \mathrm{P}<0.0001)$ (Table 1$)$.

Patients who had any calcification in the thoracic aorta were older than those without calcification (65.3 years vs 58.5 years, $\mathrm{P}=0.05)$. Furthermore, these patients were more likely to be male ( $61 \%$ vs $50 \%)$, diabetic ( $29 \%$ vs $16 \%$ ), a smoker ( $84 \%$ vs $67 \%$ ) and have chronic kidney disease ( $6 \%$ vs $0 \%$ ), although none of these associations reached statistical significance. The prevalence of hypertension (95\% vs $93 \%$ ) and dyslipidemia ( $87 \%$ vs $83 \%$ ) was nearly identical and high in both groups, with most of the patients having both ailments.

\section{Hemodynamic Indices}

The mean aortic PP in our study population was 55.5 $\pm 17.8 \mathrm{mmHg}$. Mean systolic pressure in the aorta was $122.6 \pm 20.9 \mathrm{mmHg}$, and mean diastolic pressure in the aorta was $67.1 \pm 11.6 \mathrm{mmHg}$. Mean noninvasive PP measured at the time of echocardiography was 52.4 $\pm 16 \mathrm{mmHg}$.

\section{Calcification}

The mean of the total CaSc in different segments of the aorta progressively decreased from the descending thoracic aorta to the arch of the aorta to the ascending aorta (697.2 to 571.1 to 131 , respectively; $\mathrm{P}<0.0001$ ) (Table 1). Calcium scores were three times higher among men than women, but the difference did not reach statistical significance in any segment of the aorta: ascending aorta $(\mathrm{P}=0.27)$, arch of the aorta $(\mathrm{P}=0.18)$, and descending aorta $(\mathrm{P}=0.19)$ (Table 1).

Those patients with any aortic calcification (Calcified Group A) had a much higher invasively measured PP than those without any calcification (Noncalcified Group B) (Table 2), but the difference reached statistical significance only in the descending thoracic aorta $(64.4 \mathrm{mmHg}$ in Group A vs $43.7 \mathrm{mmHg}$ in Group B, $\mathrm{P}<0.0001$ ). A visual example comparing two representative patients is shown in Figure 1. A similar but weaker trend also was seen in the other segments (Table 2). Although the prevalence of calcification was higher in the arch of the aorta (Table 2, footnote), the burden of calcific plaques was highest for the descending aorta $(\mathrm{CaSc}=697)$, followed by the arch of the aorta $(\mathrm{CaSc}=571)$ and ascending aorta $(\mathrm{CaSc}=131)$.
Table 2. Comparison of Invasive Pulse Pressure (PP) in Two Categories as Defined by Presence (Group A) or Absence (Group B) of Calcification

\begin{tabular}{lccc}
\hline $\begin{array}{l}\text { Anatomic } \\
\text { location* }\end{array}$ & $\begin{array}{c}\text { Mean PP } \\
\text { (Group A) }\end{array}$ & $\begin{array}{c}\text { Mean PP } \\
\text { (Group B) }\end{array}$ & $\boldsymbol{P}$ \\
\hline Ascending aorta & $62.5 \mathrm{mmHg}$ & $52.5 \mathrm{mmHg}$ & 0.12 \\
Arch of the aorta & $57.4 \mathrm{mmHg}$ & $51.9 \mathrm{mmHg}$ & 0.38 \\
$\begin{array}{l}\text { Descending } \\
\text { thoracic aorta }\end{array}$ & $64.4 \mathrm{mmHg}$ & $43.7 \mathrm{mmHg}$ & $<0.0001$ \\
\hline
\end{tabular}

*In the ascending aorta, a minority of patients had calcification present (11 of 37, 30\%). In the aortic arch, a majority had calcification present (24 of $37,65 \%$ ). In the descending aorta, a majority had calcification present (21 of $37,57 \%$ ).

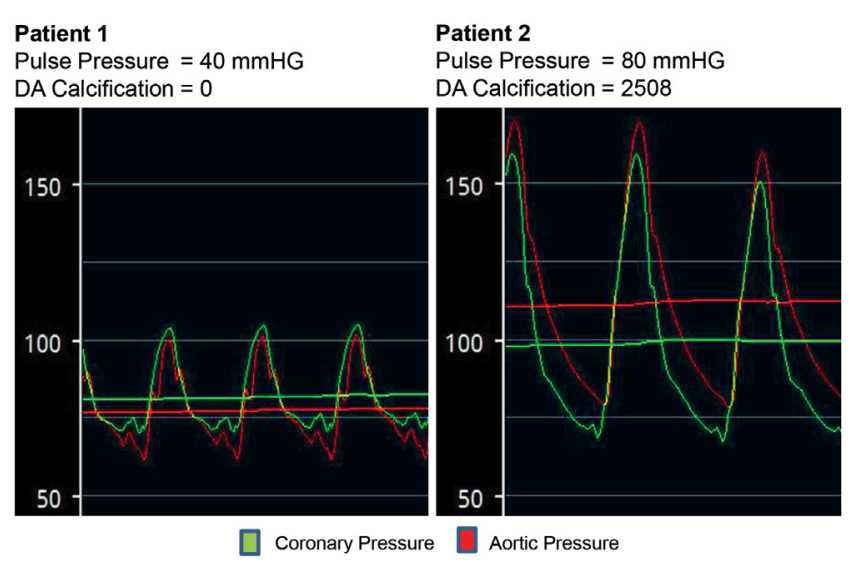

Figure 1. Aortic pressure tracings of two patients. Patient 1 had no calcification in the descending thoracic aorta (DA), whereas Patient 2 had a heavily calcified $D A$. Patient 2 had pulse pressure twice that of Patient 1.

\section{Relationship Between Hemodynamic Indices and Calcification Scores}

Invasive aortic PP was weakly associated with total $\mathrm{CaSc}$ in each aortic segment, with a positive linear relationship (Std $\beta /$ parameter estimate), respectively, that did not reach statistical significance (Table 3). These values were nearly identical to those calculated using calcium volume; therefore, calcium volume data are not shown. Of the three segments, the strongest correlation (r-value) was found in the descending aorta (Table 3). 
Table 3. Association Between Calcium Score (CaSc) and Invasive Aortic Pulse Pressure (PP)

\begin{tabular}{|c|c|c|c|c|c|c|}
\hline \multirow[b]{2}{*}{ Relationship } & \multicolumn{2}{|c|}{ Ascending aorta } & \multicolumn{2}{|c|}{ Arch of aorta } & \multicolumn{2}{|c|}{$\begin{array}{c}\text { Descending } \\
\text { thoracic aorta }\end{array}$} \\
\hline & Std $\beta$ & $r$ & Std $\beta$ & $r$ & Std $\beta$ & $r$ \\
\hline Total CaSc and PP & $\begin{array}{c}0.24 \\
(P=0.15)\end{array}$ & $\begin{array}{c}0.3 \\
(P=0.08)\end{array}$ & $\begin{array}{c}0.25 \\
(P=0.14)\end{array}$ & $\begin{array}{c}0.28 \\
(P=0.1)\end{array}$ & $\begin{array}{c}0.13 \\
(P=0.43)\end{array}$ & $\begin{array}{c}0.47 \\
(P=0.003)\end{array}$ \\
\hline Mean CaSc and PP & $\begin{array}{c}0.24 \\
(P=0.15)\end{array}$ & $\begin{array}{c}0.27 \\
(P=0.09)\end{array}$ & $\begin{array}{c}0.11 \\
(P=0.52)\end{array}$ & $\begin{array}{c}0.28 \\
(P=0.95)\end{array}$ & $\begin{array}{c}0.43 \\
(P=0.008)^{*}\end{array}$ & $\begin{array}{c}0.46 \\
(P=0.004)\end{array}$ \\
\hline
\end{tabular}

*The association between descending aorta mean calcification score and pulse pressure persisted after adjustment for age, gender, diabetes, dyslipidemia, hypertension and smoking, with standardized $\beta$ (Std $\beta$ ) decreasing from 0.43 to 0.428 and $P$-value decreasing in significance from 0.008 to 0.03 .

Comparing aortic PP with mean CaSc again revealed a positive linear association (Std $\beta /$ parameter estimate) for each aortic segment. Under this linear regression analysis, however, the association did reach statistical significance in the descending aorta (Std $\beta=0.43$, $\mathrm{P}=0.008$ ) and this significance persisted after adjusting for age, gender, diabetes, dyslipidemia, hypertension and smoking (Table 3). After adjustment, the Std $\beta$ slid from 0.43 to 0.428 and P-value from 0.008 to 0.03 .

Spearman's correlation r-value showed a similar pattern of increasing "goodness of fit" between mean calcification and PP from the ascending aorta segment to the arch to the descending aorta (Table 3). This correlation reached statistical significance only in the descending aorta $(\mathrm{r}=0.46, \mathrm{P}=0.004)$.

\section{Compliance}

The mean aortic compliance using noninvasive PP measurement was $1.49 \pm 0.65 \mathrm{~mL} / \mathrm{mmHg}$ and was nearly identical to that calculated using invasively measured PP $(1.48 \pm 0.57 \mathrm{~mL} / \mathrm{mmHg})$.

\section{Invasively Measured Compliance}

Aortic compliance was consistently lower in Calcified Group A than Noncalcified Group B across all segments of the aorta (Figure 2). This difference was greatest and statistically significant in the descending aorta $(0.71 \mathrm{~mL} / \mathrm{mmHg}, \mathrm{P}=0.002)$. The difference in compliance was not significant in the arch of the aorta $(0.15 \mathrm{~mL} / \mathrm{mmHg}, \mathrm{P}=0.6)$. However, compliance was significantly lower for Calcified Group A in the ascending aorta $(0.54 \mathrm{~mL} / \mathrm{mmHg}, \mathrm{P}=0.03)$.

\section{Noninvasively Measured Compliance}

Compliance of different segments of the aorta decreased with presence of calcification in the respective segments. The difference in compliance between groups was greatest in the descending aorta $(1.34 \mathrm{~mL} / \mathrm{mmHg}$ for Calcified Group A vs $1.69 \mathrm{~mL} / \mathrm{mmHg}$ for Noncalcified Group B) but not statistically significant $(\mathrm{P}=0.09)$.

Invasive PP was inversely related to the echocardiographically calculated (noninvasive) compliance of the aorta, with $\beta=-0.28$, but did not achieve statistical significance $(\mathrm{P}=0.13)$.

\section{Survival Analysis}

The median survival/follow-up time was 3.91 years (mean: 3.72 , range: 0.26 to 5.24). Out of 37 patients, 4 died; of the 4, all had calcification in the descending aorta and 3 had calcification in either the ascending aorta or the arch of the aorta.

Calcification in the ascending aorta was significantly and meaningfully associated with increased risk of mortality compared with those without calcification (hazard ratio: 7.96, 95\% confidence interval: $1.02-160.98, \mathrm{P}=0.048$ ). The hazard ratio for the descending aorta calcification group was not calculable due to the absence of a comparison group, ie, all 4 deaths occurred in those with calcification. The arch of the aorta was not significantly associated with mortality (hazard ratio: $1.7, \mathrm{P}=0.64$ ).

Of the 4 deaths, 2 patients died as a result of congestive heart failure and 1 of pneumonia. Cause of death of the fourth patient was unknown. 


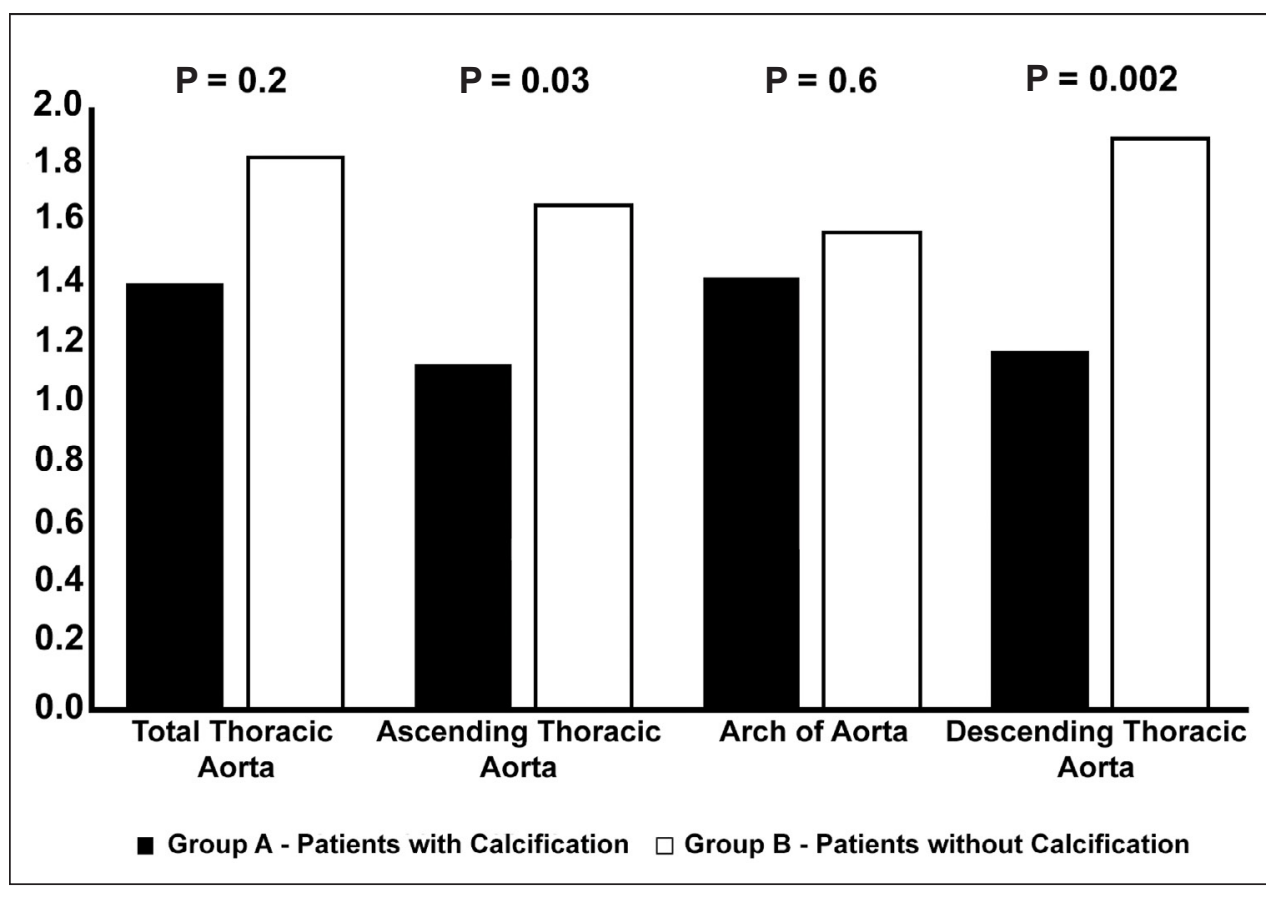

Figure 2. Comparison of mean aortic compliance between subgroups using peripheral pulse pressures. Decreasing compliance is seen in different segments of the aorta due to the presence of calcification in this comparison of two groups, one with calcification and one without. While Group A generally has lower compliance, this relationship is statistically significant only in the descending thoracic aorta. When noninvasive pulse pressure was used instead of invasive pulse pressure, results followed the same trend.

\section{DISCUSSION}

These are the first data that demonstrate the impact of varying calcification in different segments of the thoracic aorta on PP. Our results show the greatest calcification was in the descending aorta. A larger change in PP and compliance also was observed in patients with calcification in the descending aorta than in other aortic segments. A visual example of this association is shown in Figure 3.

Men had three times or more calcification than women, which, although not statistically significant, is in concurrence with previous reports. ${ }^{11}$ Men were more likely to be smokers than women, with the difference reaching statistical significance $(\mathrm{P}<0.0001)$. This finding, along with greater amounts of calcification being found in men, correlates with the already established link between smoking and atherosclerotic calcification. ${ }^{12}$

The finding of an increasing number of calcified lesions from the ascending aorta down to the descending thoracic aorta is concurrent with a prior study of 970 subjects undergoing noncontrast CT scan of the chest. ${ }^{7}$ In that study, the maximum number of calcific lesions were seen in the proximal descending aorta $(\mathrm{n}=3,824)$, followed by the mid- and distal descending aorta $(n=3,421)$, then the arch $(n=2,803)$. A minimal number of calcified lesions were seen in the ascending aorta $(n=783)$. The replication of results from another independently performed study regarding the pattern of aortic calcification renders external validity to our results. Prior studies have shown a similar mean PP (48.3 $\mathrm{mmHg}$ ) to our study patients, although they were carried out on calcifications in other arteries (ie, carotid, femoral and iliofemoral).,

Stratifying the data into groups with and without calcification showed that presence of calcification was associated with an increase in PP in all segments of the aorta, with the greatest and most significant change observed in the descending aorta (Tables 2 and 3, Figure 2). Interestingly, we also observed that aortic calcification was associated with loss of anacrotic and dicrotic notch (Figure 1). This novel finding will be addressed in a separate manuscript.

Compliance in our patients was measured using the Windkessel model (formula: SV/PP). Although compliance of vessels is distributed along the entire arterial system, Stergiopulos et al showed the major component is derived from the aorta. ${ }^{13}$ The compliance 

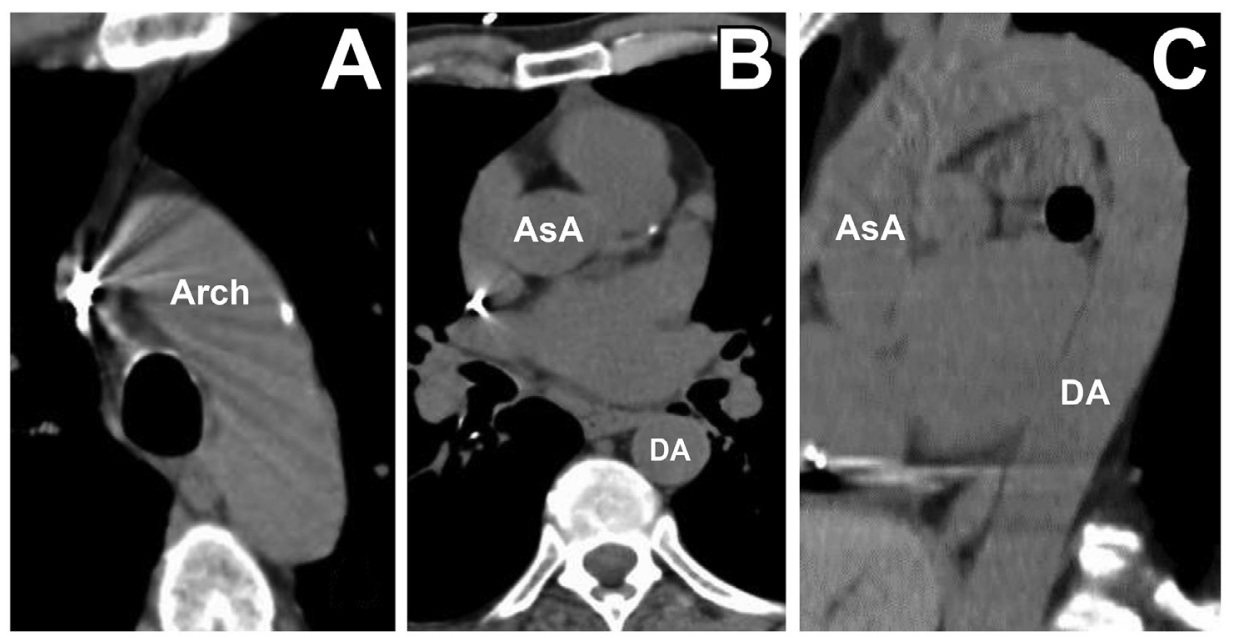

\section{Patient 1 \\ Descending Aortic \\ $\mathrm{CaSc}=0$ \\ Pulse Pressure = \\ $32 \mathrm{mmHG}$}

Aortic Compliance $=$

$2.15 \mathrm{ml} / \mathrm{mmHG}$
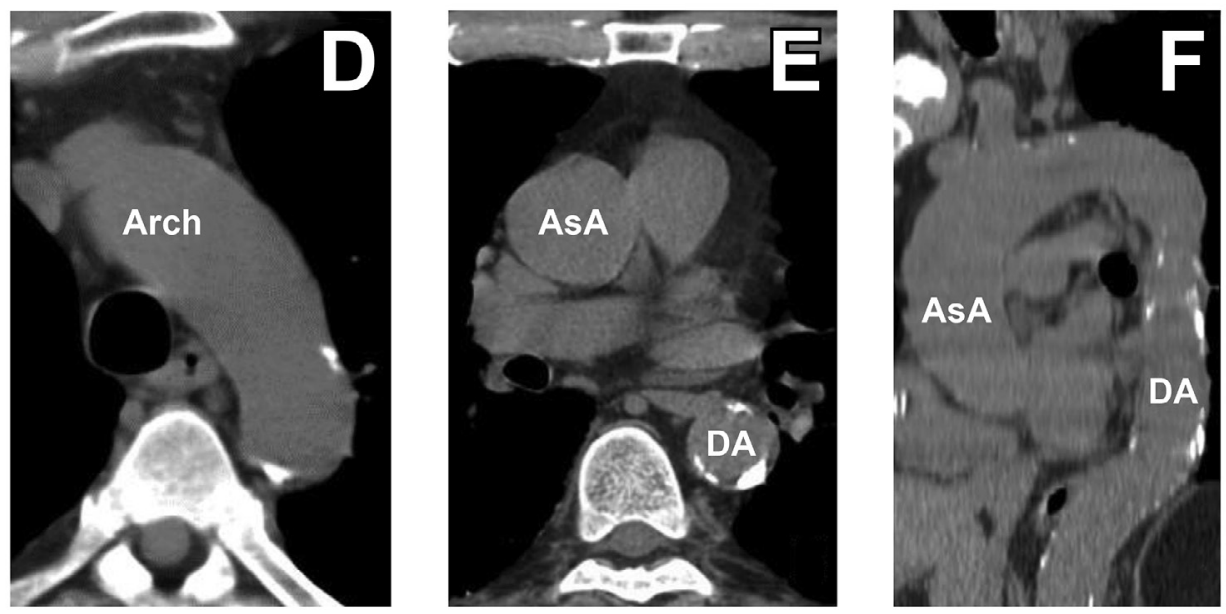

\section{Patient 2}

Descending Aortic

$\mathrm{CaSc}=\mathbf{5 0 8 0}$

Pulse Pressure $=$ $74 \mathrm{mmHG}$

Aortic Compliance $=$ $0.84 \mathrm{ml} / \mathrm{mmHG}$

Figure 3. Comparison of two patients' aortas as seen on computed tomography. Patient 1 has almost no aortic calcification (Panels A-C), which is associated with higher compliance and lower pulse pressure. Patient 2 has a heavily calcified descending thoracic aorta (Panels $E$ and F), whereas the arch of the aorta (Panel D) and ascending aorta are relatively free of calcification; this is associated with lower compliance (about one-third that of Patient 1) and higher pulse pressure (by >2-fold). Arch, arch of the aorta; AsA, ascending aorta; CaSc, calcium score; DA, descending aorta.

measured by the aforementioned formula was found to be comparable to the decay time method of calculating compliance. ${ }^{14}$

No exact range for normal compliance has been suggested. Our mean compliance is lower than the values calculated in studies using similar methods, ${ }^{15,16}$ which range from $1.5 \mathrm{~mL} / \mathrm{mmHg}$ in heart failure patients to $2 \mathrm{~mL} / \mathrm{mmHg}$ in healthy adults, with values varying among populations with different risk factors (eg, hypertension, coronary artery disease). The mean age in these studies was significantly lower than in our population (53 vs 64 years). So while our overall value of compliance $(1.48 \mathrm{~mL} / \mathrm{mmHg})$ was lower in comparison, it was not outside the expected range for a population that included older and sicker patients with significantly calcified aortas.

We used two values for PP. One was taken at the time of cardiac catheterization and the other at the time echocardiography was performed. Both methods showed similar trends of decreasing compliance with increasing calcification in different segments of the aorta, with the largest and statistically significant change observed in the descending thoracic aorta. One explanation for this is that the greatest amount of calcification was observed in this segment, resulting in arterial stiffening that decreases distensibility of the arteries. ${ }^{4}$ 
Craiem et al previously reported differential distribution of calcification among aortic segments, with the percentage of calcification decreasing from $66 \%$ for the descending aorta to $25 \%$ for the arch to 9\% for the ascending aorta. ${ }^{7}$ Agmon et al, based on transesophageal echocardiography, demonstrated a decreasing burden of calcific plaque from the descending aorta $(45 \%)$ to the arch $(31 \%)$ to the ascending aorta $(8 \%),{ }^{17}$ further validating our findings. However, there has been controversy regarding this pattern of calcification in the published literature. Takasu et al found calcifications predominantly in the aortic arch, as did another Japanese cohort. ${ }^{18,19}$

This heterogeneous pattern of thoracic aortic calcification is an unexplained observation. Multiple mechanisms have been proposed, including altered low-density-lipoprotein cholesterol transportation ${ }^{20,21}$ and increased turbulence and wall shear stress, especially in the location of the descending aorta, which has many more branches than the other segments. ${ }^{22-24}$ For instance, the ascending aorta only has two branches (right and left coronary artery), and the arch has three branches (brachiocephalic, right subclavian, right common carotid). However, the descending aorta has multiple branches, including 11 pairs of posterior intercostal arteries and multiple arteries originating anteriorly, including bronchial, mediastinal, esophageal and pericardial branches as well as superior phrenic arteries.

The variation in aortic compliance may be related to congenital or acquired issues. Histological studies have shown a decreasing number of elastic lamellae as one moves from the ascending aorta to the descending aorta. ${ }^{8}$ While these findings may not apply to an older patient population with multiple comorbidities - as typically present in those being investigated for cardiovascular disease - they represent the most relevant available literature on the pathology of elastic fibers in humans. In addition, with increasing age, elastic lamellae are fragmented and disrupted, the collagen-to-elastin ratio is altered and wall calcification increases, leading to increased PP, which has been shown to increase the risk for coronary artery disease. ${ }^{25}$

Although our survival data were limited by only 4 events in a small sample of 37 patients, it is noteworthy that all the deaths happened in those patients who had calcification present in the thoracic aorta. Any calcification present in the ascending aorta was associated with an 8-fold increased risk of mortality, and any calcification present in the descending aorta was associated with an incalculably (4:0) higher risk of mortality due to zero cell issue. At least $50 \%$ of deaths were related to cardiac etiology in our small dataset, supporting the prognostic significance hypothesis of $\mathrm{PP}$ in regard to cardiac death.

There are no clinically available treatments targeted at improving PP via improved compliance of vessels or arterial decalcification. The clinical relevance of arterial decalcification would be in the improvement of PP, which should result in improved cardiovascular morbidity and mortality. In human renal failure patients, in whom vascular calcification is very common, a high dose of vitamin $\mathrm{D}$ and aluminum hydroxide led to reversal of vascular calcification in two patients. ${ }^{26}$

In rats, regression of arterial calcification and improvement in arterial compliance by high intake of vitamin $\mathrm{K}$ has been documented. ${ }^{27}$ This effect was likely mediated by the matrix G1a protein (MGP), which is a potent inhibitor of arterial calcification and requires vitamin $\mathrm{K}$ for its activity. In addition, inhibition of MGP by a vitamin $\mathrm{K}$ antagonist, warfarin, was shown to accelerate arterial calcification. The recently approved calcimimetic etelcalcetide (Amgen Inc., Thousand Oaks, CA) attenuated arterial calcification in uremic rats with renal failure, as compared to calcitriol or placebo. ${ }^{28}$

The current data further our understanding of the mechanism behind increased PP as a function of calcification predominantly in the descending aorta. In the future, if a treatment becomes clinically available for arterial calcification and elevated PP, then calcium scoring of the descending aorta may help further risk stratification and lead to superior patient selection.

\section{Limitations}

The small sample size in our study was reflected by lack of statistical significance reached in some of the associations. The cross-sectional nature of the study limits our ability to infer a cause-effect relationship. 
In an ideal setting, all the studies - ie, echocardiography, $\mathrm{CT}$ and aortic pressure measurements - would be simultaneously performed. Practically, a calcified aorta is unlikely to change within a year's time, which is why we chose CT scans and echocardiography done within a year of aortic pressure measurements. While combining the data from two laboratories (echocardiography and catheterization) provides the ability to generate insights, these are built on a weak assumption; therefore, these results are at best hypothesis-generating.

Also, patient information regarding presence of peripheral vascular disease or connective tissue disease, use of medications influencing extracellular matrix or calcium homeostasis, and simultaneous blood pressures by cuff were not available. Sedation may have affected the measurement of blood pressure during invasive procedures, although it is worth noting that results were similar between invasive and noninvasive measurements.

The formula for aortic compliance assumes the same SV throughout the entire aorta. While this formula has been used in the literature, ${ }^{13}$ the SV likely would decrease between the ascending and descending aorta due to blood flowing out into the coronaries, arch vessels and intercostal arteries. The theoretical segmental change in $\mathrm{PP}$ and compliance in different segments of the thoracic aorta can be accurately measured in a prospective study in which PP is measured in the cardiac catheterization laboratory with the catheter parked sequentially in the ascending aorta, arch and descending aorta. Similarly, the regional SVs in different aortic segments can be measured in the echocardiography laboratory by sampling blood flow from different segments. Because the current study suffers from lack of segmental PP and SV measurements, observations that escape this limitation are those based on the ascending aorta for $\mathrm{SV}$, compliance and $\mathrm{PP}$, or direct measurements of calcification in the descending aorta, ascending aorta and arch.

\section{CONCLUSIONS}

The greatest amount of calcification in the thoracic aorta - and greatest changes in pulse pressure and compliance - occurs in the descending aorta, which makes a case for the descending aorta playing a major role in pulse pressure as compared to other aortic segments. The clinical implications of these data may become apparent if therapies targeting arterial decalcification become clinically available.

\section{Patient-Friendly Recap}

- Pulse pressure is the difference between systolic and diastolic blood pressures. When calcium deposits form in arterial walls, wall elasticity decreases, resulting in increased pulse pressure. More calcification makes the artery less elastic, further elevating health risk.

- The authors studied the distribution of calcification in the thoracic aorta (the chest portion of the body's largest artery) and found that, of its three segments, the descending aorta was most affected.

- Higher pulse pressure and lower aortic elasticity were most associated with calcification in the descending aorta.

- As treatments combating calcification of artery walls emerge, evaluation of the descending aorta could provide helpful prognostic information.

\section{Acknowledgments}

The authors gratefully acknowledge Jennifer Pfaff and Susan Nord of Aurora Cardiovascular Services for editorial preparation of the manuscript and Brian Schurrer and Brian Miller of Aurora Research Institute (Milwaukee, WI) for help with the figures.

\section{Conflicts of Interest}

None.

\section{References}

1. de Simone G, Roman MJ, Daniels SR, et al. Age-related changes in total arterial capacitance from birth to maturity in a normotensive population. Hypertension. 1997;29:1213-7. CrossRef

2. de Simone G, Roman MJ, Koren MJ, Mensah GA, Ganau A, Devereux RB. Stroke volume/pulse pressure ratio and cardiovascular risk in arterial hypertension. Hypertension. 1999;33:800-5. CrossRef

3. Benetos A, Rudnichi A, Safar M, Guize L. Pulse pressure and cardiovascular mortality in normotensive and hypertensive subjects. Hypertension. 1998;32:560-4. CrossRef 
4. Jensky NE, Criqui MH, Wright MC, Wassel CL, Brody SA, Allison MA. Blood pressure and vascular calcification. Hypertension. 2010;55:990-7. CrossRef

5. Blacher J, Guerin AP, Pannier B, Marchais SJ, London GM. Arterial calcifications, arterial stiffness, and cardiovascular risk in end-stage renal disease. Hypertension. 2001;38:938-42. CrossRef

6. Miwa Y, Tsushima M, Arima H, Kawano Y, Sasaguri T. Pulse pressure is an independent predictor for the progression of aortic wall calcification in patients with controlled hyperlipidemia. Hypertension. 2004;43:536-40. CrossRef

7. Craiem D, Chironi G, Casciaro ME, Graf S, Simon A. Calcifications of the thoracic aorta on extended non-contrastenhanced cardiac CT. PLoS One. 2014;9:e109584. CrossRef

8. Wolinsky H, Glagov S. Comparison of abdominal and thoracic aortic medial structure in mammals. Deviation of man from the usual pattern. Circ Res. 1969;25:677-86. CrossRef

9. Westerhof N, Lankhaar JW, Westerhof BE. The arterial Windkessel. Med Biol Eng Comput. 2009;47:131-41. CrossRef

10. Budoff MJ, Nasir K, Kinney GL, et al. Coronary artery and thoracic calcium on noncontrast thoracic CT scans: comparison of ungated and gated examinations in patients from the COPD Gene cohort. J Cardiovasc Comput Tomogr. 2011;5:113-8. CrossRef

11. Schoen FJ. Blood vessels. In: Cotran RS, Kumar V, Collins T (eds). Robbins Pathologic Basis of Disease, Sixth Edition. London, UK: W.B. Saunders, 1999, pp. 493-541.

12. Auerbach O, Garfinkel L. Atherosclerosis and aneurysm of aorta in relation to smoking habits and age. Chest. 1980;78:805-9. CrossRef

13. Stergiopulos N, Segers P, Westerhof N. Use of pulse pressure method for estimating total arterial compliance in vivo. Am J Physiol. 1999;276:H424-8.

14. Stergiopulos N, Westerhof BE, Westerhof N. Total arterial inertance as the fourth element of the windkessel model. Am J Physiol. 1999;276:H81-8.

15. Duprez DA, De Buyzere ML, Rietzschel ER, et al. Inverse relationship between aldosterone and large artery compliance in chronically treated heart failure patients. Eur Heart $J$. 1998;19:1371-6. CrossRef

16. Cohn JN, Finkelstein S, McVeigh G, et al. Noninvasive pulse wave analysis for the early detection of vascular disease. Hypertension. 1995;26:503-8. CrossRef

17. Agmon Y, Khandheria BK, Meissner I, et al. Independent association of high blood pressure and aortic atherosclerosis: a population-based study. Circulation. 2000;102:2087-93. $\underline{\text { CrossRef }}$
18. Takasu J, Takanashi K, Naito S, et al. Evaluation of morphological changes of the atherosclerotic aorta by enhanced computed tomography. Atherosclerosis. 1992;97:107-21. CrossRef

19. Itani $Y$, Watanabe $S$, Masuda Y. Aortic calcification detected in a mass chest screening program using a mobile helical computed tomography unit. Relationship to risk factors and coronary artery disease. Circ J. 2004;68:538-41. CrossRef

20. Giddens DP, Zarins CK, Glagov S. The role of fluid mechanics in the localization and detection of atherosclerosis. J Biomech Eng. 1993;115:588-94. CrossRef

21. Liu X, Pu F, Fan Y, Deng X, Li D, Li S. A numerical study on the flow of blood and the transport of LDL in the human aorta: the physiological significance of the helical flow in the aortic arch. Am J Physiol Heart Circ Physiol. 2009;297:H163-70. CrossRef

22. Shahcheraghi N, Dwyer HA, Cheer AY, Barakat AI, Rutaganira T. Unsteady and three-dimensional simulation of blood flow in the human aortic arch. $J$ Biomech Eng. 2002;124:378-87. CrossRef

23. Suo J, Ferrara DE, Sorescu D, Guldberg RE, Taylor WR, Giddens DP. Hemodynamic shear stresses in mouse aortas: implications for atherogenesis. Arterioscler Thromb Vasc Biol. 2007; 27:346-51. CrossRef

24. Vincent PE, Plata AM, Hunt AA, Weinberg PD, Sherwin SJ. Blood flow in the rabbit aortic arch and descending thoracic aorta. J R Soc Interface. 2011;8:1708-19. CrossRef

25. Steppan J, Barodka V, Berkowitz DE, Nyhan D. Vascular stiffness and increased pulse pressure in the aging cardiovascular system. Cardiol Res Pract. 2011;2011:263585. CrossRef

26. Verberckmoes R, Bouillon R, Krempien B. Disappearance of vascular calcifications during treatment of renal osteodystrophy. Two patients treated with high doses of vitamin $\mathrm{D}$ and aluminum hydroxide. Ann Intern Med. 1975;82:529-33. CrossRef

27. Schurgers LJ, Spronk HM, Soute BA, Schiffers PM, DeMey $\mathrm{JG}$, Vermeer C. Regression of warfarin-induced medial elastocalcinosis by high intake of vitamin $\mathrm{K}$ in rats. Blood. 2007;109:2823-31. CrossRef

28. Henley C, Davis J, Miller G, et al. The calcimimetic AMG 641 abrogates parathyroid hyperplasia, bone and vascular calcification abnormalities in uremic rats. Eur J Pharmacol. 2009;616:306-13. CrossRef

(C) 2017 Aurora Health Care, Inc. 